\title{
Techniques and long-term outcomes of cotton-clipping and cotton-augmentation strategies for management of cerebral aneurysms
}

\author{
Sam Safavi-Abbasi, MD, PhD, ${ }^{1}$ Felix Moron, MD, ${ }^{2}$ Hai Sun, MD, PhD, ${ }^{1}$ Mark E. Oppenlander, MD, ${ }^{1}$ \\ M. Yashar S. Kalani, MD, PhD, ${ }^{1}$ Celene B. Mulholland, MD, MPH, ${ }^{1}$ Joseph M. Zabramski, MD, ${ }^{1}$ \\ Peter Nakaji, MD, ${ }^{1}$ and Robert F. Spetzler, MD'
}

'Division of Neurological Surgery, Barrow Neurological Institute, St. Joseph's Hospital and Medical Center, Phoenix, Arizona; and 2Division of Neurological Surgery, Hospital Interzonal General de Agudos Vicente Lopez y Planes, Buenos Aires, Argentina

OBJECTIVE To address the challenges of microsurgically treating broad-based, frail, and otherwise complex aneurysms that are not amenable to direct clipping, alternative techniques have been developed. One such technique is to use cotton to augment clipping ("cotton-clipping" technique), which is also used to manage intraoperative aneurysm neck rupture, and another is to reinforce unclippable segments or remnants of aneurysm necks with cotton ("cottonaugmentation" technique). This study reviews the natural history of patients with aneurysms treated with cotton-clipping and cotton-augmentation techniques.

METHODS The authors queried a database consisting of all patients with aneurysms treated at Barrow Neurological Institute in Phoenix, Arizona, between January 1, 2004, and December 31, 2014, to identify cases in which cotton-clipping or cotton-augmentation strategies had been used. Management was categorized as the cotton-clipping technique if cotton was used within the blades of the aneurysm clip and as the cotton-clipping technique if cotton was used to reinforce aneurysms or portions of the aneurysm that were unclippable due to the presence of perforators, atherosclerosis, or residual aneurysms. Data were reviewed to assess patient outcomes and annual rates of aneurysm recurrence or hemorrhage after the initial procedures were performed.

RESULTS The authors identified 60 aneurysms treated with these techniques in 57 patients (18 patients with ruptured aneurysms and 39 patients with unruptured aneurysms) whose mean age was 53.1 years (median 55 years; range 24-72 years). Twenty-three aneurysms (11 cases of subarachnoid hemorrhage) were treated using cotton-clipping and 37 with cotton-augmentation techniques (7 cases of subarachnoid hemorrhage). In total, 18 patients presented with subarachnoid hemorrhage. The mean Glasgow Outcome Scale (GOS) score at the time of discharge was 4.4. At a mean follow-up of $60.9 \pm 35.6$ months (median 70 months; range 10-126 months), the mean GOS score at last follow-up was 4.8. The total number of patient follow-up years was 289.4. During the follow-up period, none of the cotton-clipped aneurysms increased in size, changed in configuration, or rebled. None of the patients experienced early rebleeding. The annual hemorrhage rate for aneurysms treated with cotton-augmentation was $0.52 \%$ and the recurrence rate was $1.03 \%$ per year. For all patients in the study, the overall risk of hemorrhage was $0.35 \%$ per year and the annual recurrence rate was $0.69 \%$.

CONCLUSIONS Cotton-clipping is an effective and durable treatment strategy for intraoperative aneurysm rupture and for management of broad-based aneurysms. Cotton-augmentation can be safely used to manage unclippable or partially clipped intracranial aneurysms and affords protection from early aneurysm re-rupture and a relatively low rate of late rehemorrhage.

http://thejns.org/doi/abs/10.3171/2015.7.JNS151165

KEY WORDS cotton-clipping technique; cotton-augmentation technique; microsurgery; microsurgical clipping; cerebral aneurysm; ruptured aneurysm; unruptured aneurysm; subarachnoid hemorrhage; vascular disorders

ABBREVIATIONS $\mathrm{ACOA}=$ anterior communicating artery; $\mathrm{CTA}=\mathrm{CT}$ angiography; $\mathrm{GOS}=$ Glasgow Outcome Scale .

SUBMITTED May 19, 2015. ACCEPTED July 15, 2015.

INCLUDE WHEN CITING Published online January 15, 2016; DOI: 10.3171/2015.7.JNS151165. 
$\mathrm{M}$ ICROSURGICAL management of broad-based, frail, or blister-like aneurysms may be particularly challenging due to their propensity to rupture intraoperatively, as well as the lack of an identifiable neck. ${ }^{14,15,35}$ Fusiform, dysplastic, and otherwise complex aneurysms may not be amenable to direct clipping and may require alternative management strategies. . $^{1,3,11,15-17,26,33,34,65}$ We have previously reported our experience with wrapping and clip-wrapping these types of aneurysms with cotton. ${ }^{15,35}$ However, our wrapping strategies have evolved over the past decade, and we now most frequently use Gore-Tex membrane (W. L. Gore \& Associates, Inc.) when circumferentially wrapping unclippable aneurysms. We use cotton to augment clipping of segments of aneurysms that cannot be wrapped circumferentially due to the presence of perforators or aneurysms that cannot be clipped primarily.

We have previously used the "cotton-clipping" technique to manage intraoperative ruptures or tears in the aneurysm neck or parent vessel, $, 2,42,60$ as well as to bolster clipping in cases in which slippage of the clip is a risk..$^{33,34}$ Furthermore, we have frequently used the "cotton-augmentation" technique to reinforce unclippable segments of an aneurysm or small remnants of aneurysm necks, the socalled dog-ears, between the parent vessel and the base of the clip..$^{14}$ However, few reports are available on the longterm safety and angiographic durability of cotton-clipping strategies. We now report a contemporary series on the long-term clinical and radiographic follow-up of patients with aneurysms treated with cotton-clipping and cottonaugmentation techniques.

\section{Methods}

A database consisting of all patients with aneurysms treated at Barrow Neurological Institute between January 1, 2004, and December 31, 2014, was queried to identify all cases in which cotton-clipping or cotton-augmentation strategies were used. This retrospective review study was approved by the institutional review board of St. Joseph's Hospital and Medical Center, Phoenix, Arizona. Because of the retrospective nature of the review, the study was exempted from informed consent requirements.

Management was categorized as the cotton-clipping technique if cotton was used within the blades of the aneurysm clip (Videos 1 and 2) and as the cotton-augmentation technique if cotton was used to reinforce aneurysms or parts of aneurysms (so-called dog-ears) that were unclippable due to perforators, atherosclerosis, or unclipped aneurysm areas between the clip blades (Fig. 1, Video 3).

VIDEO 1. Video clip shows the cotton-clipping technique of a small, fragile, blister-like ACoA aneurysm. Because the ACoA is fenestrated, there is no concern about circumferential placement of cotton around the aneurysm and parent vessel. Copyright Barrow Neurological Institute. Published with permission. Click here to view.

VIDEO 2. Video clip shows a small, fragile, broad-based aneurysm that is clipped with the cotton-clipping technique to increase the surface area prior to clipping, as well as to avoid clip slippage and aneurysm neck or parent vessel tear. Copyright Barrow Neurological Institute. Published with permission. Click here to view.

VIDEO 3. Video clip demonstrates simple cotton-augmentation of a basilar tip aneurysm to reinforce an unclipped, dog-ear residuum that was left to protect perforators that are especially important in this area. Copyright Barrow Neurological Institute. Published with permission. Click here to view.

We reviewed patient sex and age; side, size, and projection of the aneurysm; symptoms at presentation; treatment modalities; complications; and outcomes for each patient. The patients' clinical examinations and imaging studies, operative and angiographic reports, and inpatient and outpatient records were reviewed. Clinical outcome was based on chart review, clinic follow-up, and telephone interviews. Patients underwent conventional catheter angiography, CT angiography (CTA), or MR angiography to evaluate changes in the size or configuration of the aneurysms. Outcomes were measured using the Glasgow Outcome Scale (GOS). Annual rates of aneurysm recurrence or hemorrhage were determined by dividing the number of clinical events (aneurysm formation or hemorrhage) by the number of patient-years of observation for the population or particular subgroup.

\section{Results}

We identified 18 patients with ruptured aneurysms and 39 patients with unruptured aneurysms who had clinical and angiographic follow-up. Overall, 60 aneurysms in 57 patients (15 male, 42 female) were treated using cottonclipping or cotton-augmentation strategies. Five patients had two aneurysms each and 7 had three or more aneurysms each. Of the 60 aneurysms treated, 23 were managed with cotton-clipping techniques (11 of these presented with subarachnoid hemorrhage) (Videos 1 and 2) and 37 with cotton-augmentation ( 7 of these presented with subarachnoid hemorrhage) (Table 1, Video 3). There were 20 small fragile, blister-like, or broad-based aneurysms; 17 saccular aneurysms; 9 atherosclerotic or calcified aneurysms; 8 giant or complex dysmorphic aneurysms; and 6 dissecting or fusiform aneurysms (Fig. 1). Most aneurysms were in the anterior circulation (Table 1, 57 aneurysms), and the orbitozygomatic and pterional approaches were most commonly used for management of these aneurysms (Table 2). The mean age of patients was 53.1 years (median 55 years; range 24-72 years). The mean length of hospital stay for patients with unruptured aneurysms was 8.5 days (median 4 days; range 1-28 days), and the mean length of hospital stay for patients who presented with ruptured aneurysms was 14.8 days (median 12 days; range 10-37 days). Among patients with ruptured aneurysms, 14 (77.8\%) required external ventricular drain placement and 7 underwent permanent shunt placement. One patient with an unruptured aneurysm required a ventriculoperitoneal shunt. Complications developed in 7 patients, including 6 who were treated for pneumonia or respiratory failure and 1 who developed a subdural hematoma that required evacuation postoperatively. There were no deaths or worsening of neurological status postoperatively. The mean GOS score at the time of discharge was 4.4 and the mean GOS score at the time of last follow-up was 4.8. Patient outcomes by treatment group are shown in Table 3. The mean follow-up was 60.9 \pm 35.6 months (median 70 months; range 10-126 months). Patient follow-up years totaled 289.4. One patient treated 

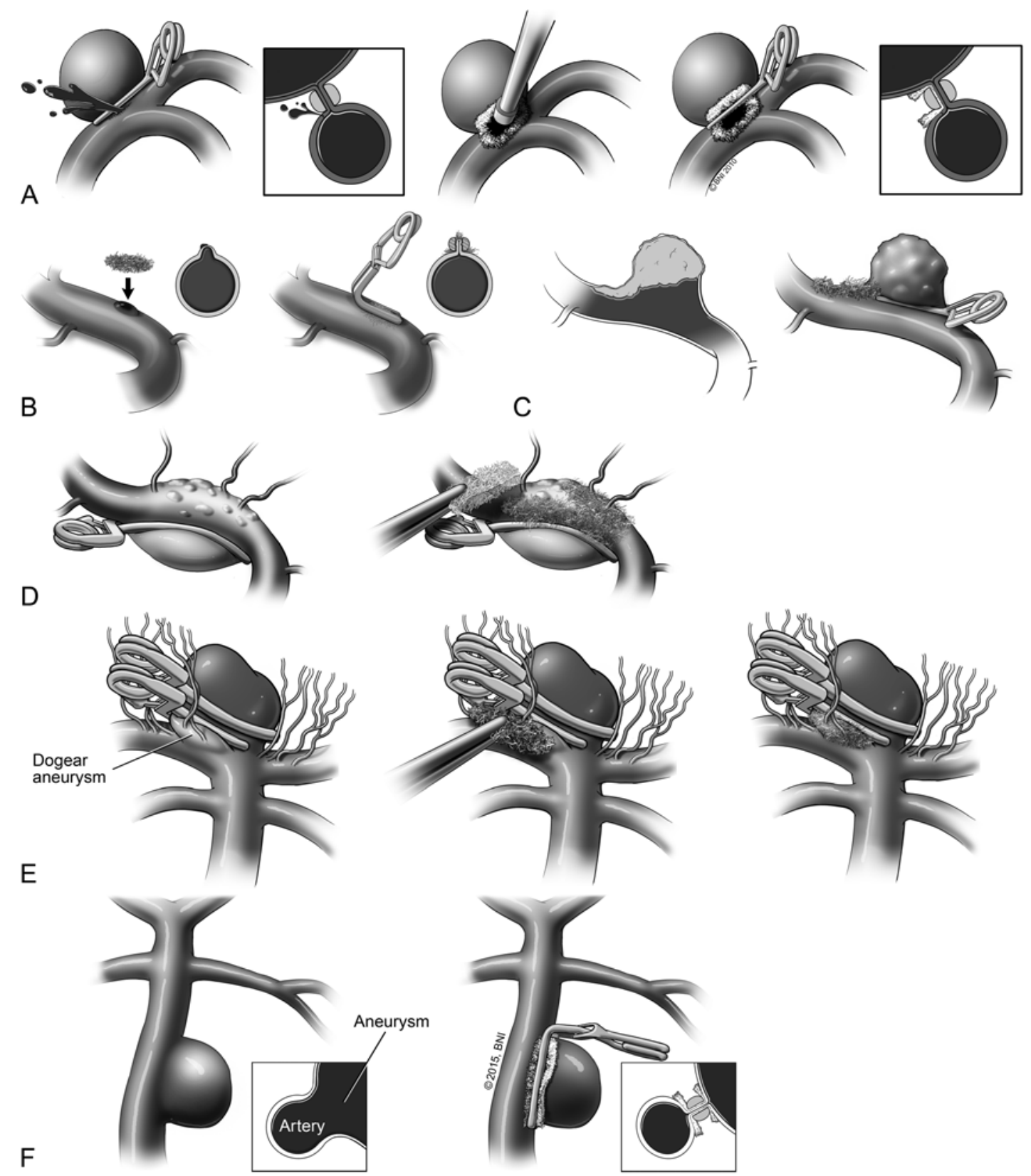

FIG. 1. Illustrations demonstrate various operative scenarios where cotton-clipping $(A, B, F)$ or cotton-augmentation $(C, D, E)$ can be used. Cross sections indicate the position of the clip and cotton. A: In case of a tear in the parent vessel or aneurysm neck, cotton can be used to cover and control the bleeding while applying suction and tamponading; the clip is applied to the cotton and the tear site. B: Cotton may be used to clip blister aneurysms. This increases the surface area and helps hold the clip, preventing parent vessel stenosis. C: Cotton-clipping and cotton-augmentation can be useful in cases of atherosclerotic, calcified vessels and aneurysm necks. Cotton may be used to prevent clip slippage and to augment unclippable aspects of the aneurysm neck. D: Cotton can also be used to augment unclippable wall changes in case of fusiform, dolichoectatic vessels that involve the entire vessel wall circumferentially. E: Cotton-augmentation can also be applied to unclippable dog-ear residua that must be left to protect perforators. F: Cotton-clipping can be applied to broad-based aneurysms to prevent clip slippage and parent vessel stenosis. Copyright Barrow Neurological Institute. Published with permission.

with cotton-augmentation sustained a rehemorrhage and 2 showed enlargement of their aneurysms on angiographic follow-up. All patients underwent subsequent successful management as outlined below. Thus, for all patients with aneurysms that were managed with either cotton-clipping or cotton-augmentation techniques, the overall risk of hemorrhage was $0.35 \%$ per year and the annual recurrence rate was $0.69 \%$ for the entire study population. Additional details on the 2 subpopulations (cotton-clipping and cotton-augmentation) are provided below. 
TABLE 1. Aneurysm location

\begin{tabular}{lccc}
\hline \multirow{2}{*}{ Aneurysm Location } & \multicolumn{3}{c}{ No. of Patients (\%) } \\
\cline { 2 - 4 } & Aneurysms & Cotton-Clipped Aneurysms & Cotton-Augmented Aneurysms \\
\hline Internal carotid artery & $7(11.7)$ & $5(21.7)$ & $2(5.4)$ \\
\hline Posterior communicating artery & $9(15.0)$ & $4(17.4)$ & $5(13.5)$ \\
\hline Ophthalmic artery & $7(11.7)$ & $1(4.3)$ & $6(16.2)$ \\
\hline Middle cerebral artery & $14(23.3)$ & $5(21.7)$ & $9(24.3)$ \\
\hline ACoA & $11(18.3)$ & $4(17.4)$ & $4(18.9)$ \\
\hline Pericallosal artery $\left(\mathrm{A}_{2} / \mathrm{A}_{3}\right.$ segment) & $6(10.0)$ & $2(8.7)$ & $1(2.7)$ \\
\hline Basilar artery & $2(3.3)$ & $1(4.3)$ & $1(2.7)$ \\
\hline Posterior inferior cerebellar artery & $2(3.3)$ & $1(4.3)$ & $1(2.7)$ \\
\hline Posterior cerebral artery $\left(\mathrm{P}_{1} / \mathrm{P}_{2}\right.$ segment) & $1(1.7)$ & $0(0.0)$ & $1(2.7)$ \\
\hline Superior cerebellar artery & $1(1.7)$ & $0(0.0)$ & $37(99.9)^{*}$ \\
\hline Total & $60(100)$ & $23(99.8)^{*}$ & \\
\hline
\end{tabular}

* Total of percentages is $<100 \%$ due to rounding.

\section{Cotton-Clipped Aneurysms}

The average follow-up for patients treated with cottonclipping was 4.1 years. Focusing only on cotton-clipped aneurysms, the corresponding observation time is $96.1 \mathrm{pa}-$ tient-years. During the follow-up period, no aneurysm that was managed with a cotton-clipping technique increased in size or changed in configuration. There were no recurrent hemorrhages in this subgroup.

\section{Cotton-Augmented Aneurysms}

There were no deaths or worsening of neurological status in patients with aneurysms who were treated with cotton-augmentation techniques. None of these patients experienced early rehemorrhage or recurrence. Two patients who were treated with partial clipping and cottonaugmentation techniques had recurrences. One patient with a cotton-augmented, small, broad-based aneurysm sustained a rehemorrhage.

The patient who experienced rebleeding had initially presented with a ruptured, small, friable, broad-based anterior communicating artery $(\mathrm{ACoA})$ aneurysm that was clipped and augmented with cotton. She then had a rehemorrhage 8 years after the initial aneurysm rupture. This patient initially presented with diffuse subarachnoid hemorrhage; however, at the time of the second hemorrhage, the patient had a localized frontal lobe hematoma. A recurrent aneurysm just adjacent to the previous clip site was detected on angiographic evaluation (Fig. 2). The aneurysm

\section{TABLE 2. Surgical approach}

\begin{tabular}{lc}
\hline Surgical Approach & No. of Cases \\
\hline Orbitozygomatic & 27 \\
\hline Pterional & 18 \\
\hline Interhemispheric & 6 \\
\hline Far lateral & 4 \\
\hline Other & 2 \\
\hline Total & 57 \\
\hline
\end{tabular}

was re-explored and again successfully clipped with cotton-augmentation of the ACoA. She remained without any neurological deficits at the time of her last follow-up, 10 years after the initial hemorrhage and 2 years after the second. On follow-up, digital subtraction angiography showed no change in the aneurysm's size or configuration 2 years after the second clipping.

The first patient with a recurrent cotton-augmented aneurysm initially presented with a complex right ophthalmic artery aneurysm and visual loss. The patient underwent an orbitozygomatic craniotomy and aneurysm clipping with 2 aneurysm clips and cotton reinforcement. Two years later, on catheter angiographic follow-up evaluation, the aneurysm was found to have increased in size and the patient underwent stent-assisted coil embolization. Again, 2 years after the endovascular procedure, the aneurysm was found to have changed in size angiographically and a pipeline embolization device was placed. One year after placement of the pipeline embolization device, she became pregnant and underwent successful delivery by cesarean section. Two years after her most recent treatment and 8 years after her initial clipping, she remains neurologically intact and the aneurysm remains completely obliterated on angiographic follow-up.

The second patient whose aneurysm recurred after clipping and cotton-augmentation was a woman who was incidentally found to have an unruptured, broad-based ACoA aneurysm with perforators originating from the base of the aneurysm. She underwent a right-sided orbitozygomatic craniotomy for partial clipping and cotton reinforcement to protect the perforators. The small residual aneurysm was followed with serial imaging, which showed an increase in size of the aneurysm 6 years after her initial surgery. She underwent microsurgical clipping of this lesion. During the surgery, the aneurysm recurred at a segment close to the previously clipped segment on the dorsal aspect of the aneurysm where there was no cotton. The recurrent segment was clipped with a second aneurysm clip. The patient remains neurologically intact and the aneurysm remains completely obliterated at 12-month angiographic follow-up. 

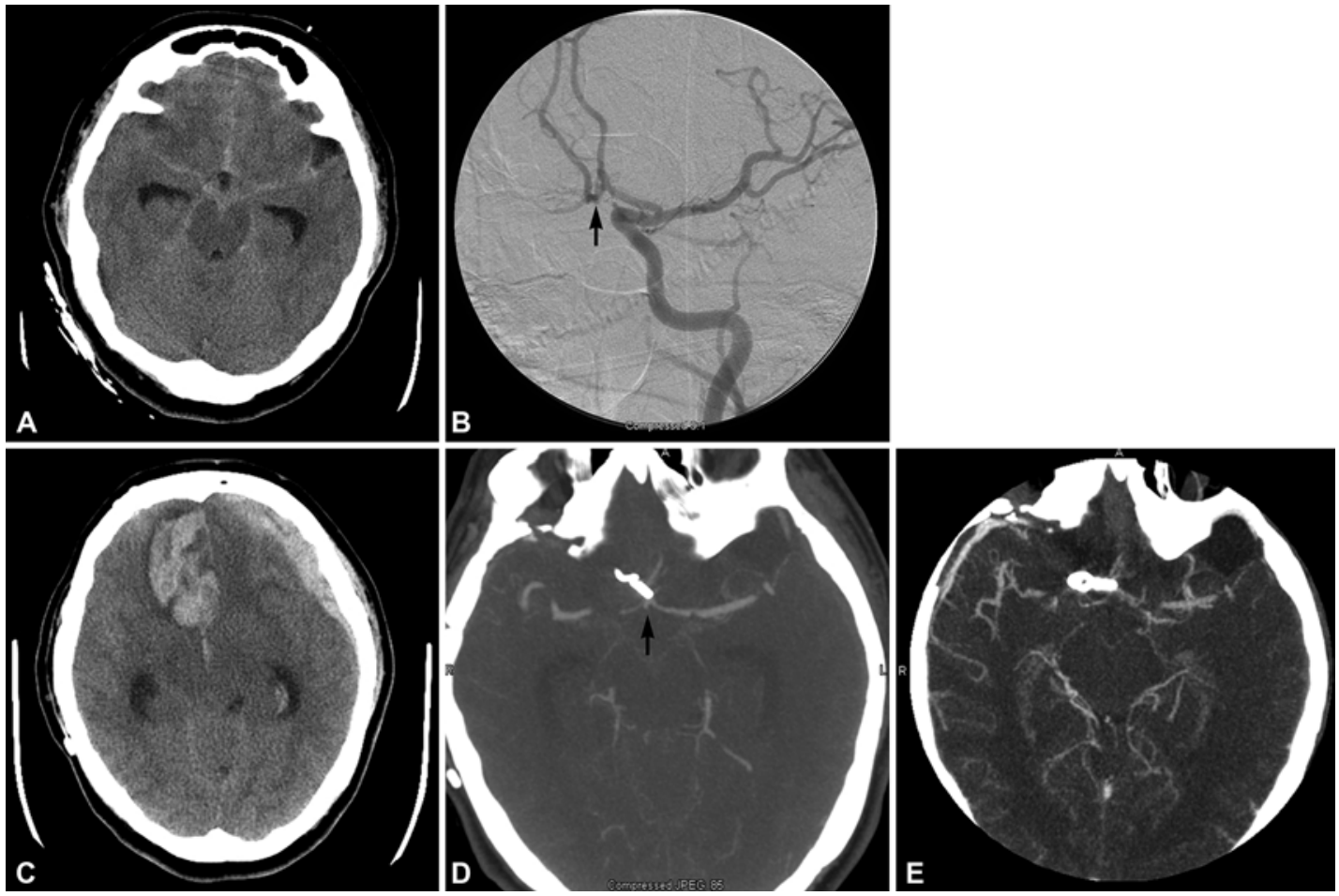

FIG. 2. Axial CT and angiographic images show the sequence of events in a patient with recurrent hemorrhage. The patient presented initially with diffuse subarachnoid hemorrhage as seen on a CT scan (A). Using CT angiographic evaluation (B), a friable, small, broad-based ACoA aneurysm was seen as the source of the hemorrhage (arrow) and was clipped. Eight years after the initial aneurysm rupture, the patient presented with rehemorrhage and CT showed a localized frontal lobe hematoma (C). An aneurysm recurrence just adjacent to the previous clip was noted on CT scan (D, arrow). This aneurysm was successfully reclipped (E) and cotton was placed around the ACoA.

For only the cotton-augmentation procedures, the average follow-up was 5.6 years and the corresponding observation time was 193.3 years. Given the 3 events (1 rebleeding aneurysm and 2 recurrences), the risk of rehemorrhage for partially clipped and cotton-augmented aneurysms was $0.52 \%$ per year and the recurrence rate for these aneurysms was $1.03 \%$ per year (Table 3 ).

\section{Discussion}

\section{Reinforcing Aneurysm Walls}

The need for follow-up data to evaluate the safety and efficacy of various treatments in the management of intracranial aneurysms has become increasingly important. ${ }^{66,68}$ Given this concern, our study was designed to determine the natural course of cotton-clipped and partially clipped cotton-augmented aneurysms. Histological examination of recurrent aneurysms has shown that arterial wall thinning and disruption of both the muscle layer and the internal elastic lamina may lead to local frailty of the arterial wall adjacent to the clipped aneurysm and may be the cause of the formation or recurrence of an aneurysm. ${ }^{19,20,24,31,50}$ Reinforcement of the residual neck and abnormal arterial wall is thought to lower the incidence of aneurysm recurrence. ${ }^{19,20,31,54}$ Several previous reports indicate that aneurysms can recur from residual aneurysm fragments, and even from apparently well-clipped aneurysms, ${ }^{14,32,47,68,69}$ and early reports stress the value of microsurgical reinforcement of incompletely obliterated aneurysm walls. ${ }^{16-18,57,67,71}$ The associations between various reinforcement materials and different rates of recurrence and postoperative bleeding have also been reported. ${ }^{12,13,15,18,26,27,40,51,52,54,55,59,61}$ In histological as well as clinical studies, cotton has been found to be the most effective reinforcement material. ${ }^{19,31,59}$ However, several reports have described complications associated with wrapping modalities, such as cranial neuropathy

TABLE 3. Results for 57 patients treated with cotton-clipping and cotton-augmentation strategies

\begin{tabular}{lccc}
\hline \multicolumn{1}{c}{ Measures } & $\begin{array}{c}\text { Cotton-Clipped Aneurysms } \\
(\mathrm{n}=23)\end{array}$ & $\begin{array}{c}\text { Cotton-Augmented Aneurysms } \\
(\mathrm{n}=37)\end{array}$ & $\begin{array}{c}\text { Total Aneurysms } \\
(\mathrm{n}=60)\end{array}$ \\
\hline Mean follow-up (years) & 4.1 & 5.6 & 5.1 \\
\hline Follow-up (patient-years) & 96.1 & 193.3 & 289.4 \\
\hline Annual recurrence rate (\%) & 0 & 1.03 & 0.69 \\
\hline Annual hemorrhage rate (\%) & 0 & 0.52 & 0.35 \\
\hline
\end{tabular}


and parent vessel stenosis. . $^{40,12,22,25,29,30,36-38,41,43,45,49,56,58,72}$ Therefore, we use cotton cautiously for circumferential wrapping of intracranial vessels. Cotton-evoked chronic inflammation, fibrosis, and granuloma formation of the adventitia may even be desired in select cases, such as in the treatment of fusiform aneurysmal dilations and aneurysm segments that cannot be completely clipped. We use small wisps of cotton and usually avoid circumferential wrapping of major vessels or placing cotton in contact with adjacent cranial nerves. In our follow-up of patients treated with cotton-clipping or cotton-augmentation, we have not encountered any complications such as vessel stenosis or cranial neuropathy.

\section{Utility and Techniques of Cotton-Clipping and Cotton-Augmentation}

The risk of regrowth of completely clipped aneurysms has been found to be much lower than the risk of de novo aneurysm formation $\left(0.26 \%\right.$ vs $0.89 \%$ annually). ${ }^{68}$ The cumulative incidence of recurrent subarachnoid hemorrhage after clipping is approximately 3\% within the initial 10 years after treatment, which emphasizes the reliability of clipping. ${ }^{62,68,70}$ However, not all aneurysms can be clipped completely. Unclippable or partially clippable aneurysms may present in various configurations. The most common variant that we have encountered is the small, fragile aneurysm without an adequate reconstructable neck. These broad-based aneurysms can be augmented with small wisps of cotton around the aneurysm base if complete clipping is not feasible (Fig. 1). Furthermore, when clipping this type of aneurysm, the challenge is to incorporate the dome of the aneurysm into the clip without compromising the lumen of the parent vessel. The wide base of the aneurysm and the small size of the dome make direct clip placement complicated and the clip may slide off, causing tears in the vessel wall or the aneurysm neck. In these cases, a piece of cotton is placed on the aneurysm or wrapped around the site of the aneurysm on the parent vessel (Videos 1 and 2); then the aneurysm is clipped over the cotton (Fig. 3). We have also used this cotton-clipping technique to treat a variety of saccular aneurysms.

Intraoperative rupture cannot be completely avoided in aneurysm surgery, especially in patients undergoing repair of ruptured aneurysms, ${ }^{21,60}$ and it has been shown that the occurrence of this complication does not diminish even as the experience of the neurosurgeon performing the surgery increases. ${ }^{44}$ Several reports have described important measures taken to control intraoperative aneurysmal rupture, including proximal and distal control for temporary clipping prior to aneurysm dissection, tamponade, suction, performing surgery with or without hypotension, and cerebral protection with hypothermia or pharmacological agents. ${ }^{28,44,46,63,64}$ In the event of an intraoperative rupture, free cotton applied to a bleeding site will tamponade the hemorrhage and provide a larger surface area where suction can be applied to facilitate visualization and clip placement. The cotton-clip construct acts as a durable bolster, which is located far enough distally on the neck to maintain patency of the parent vessel lumen (Fig. 1). We previously described the cotton-clipping technique;, $2,42,60$

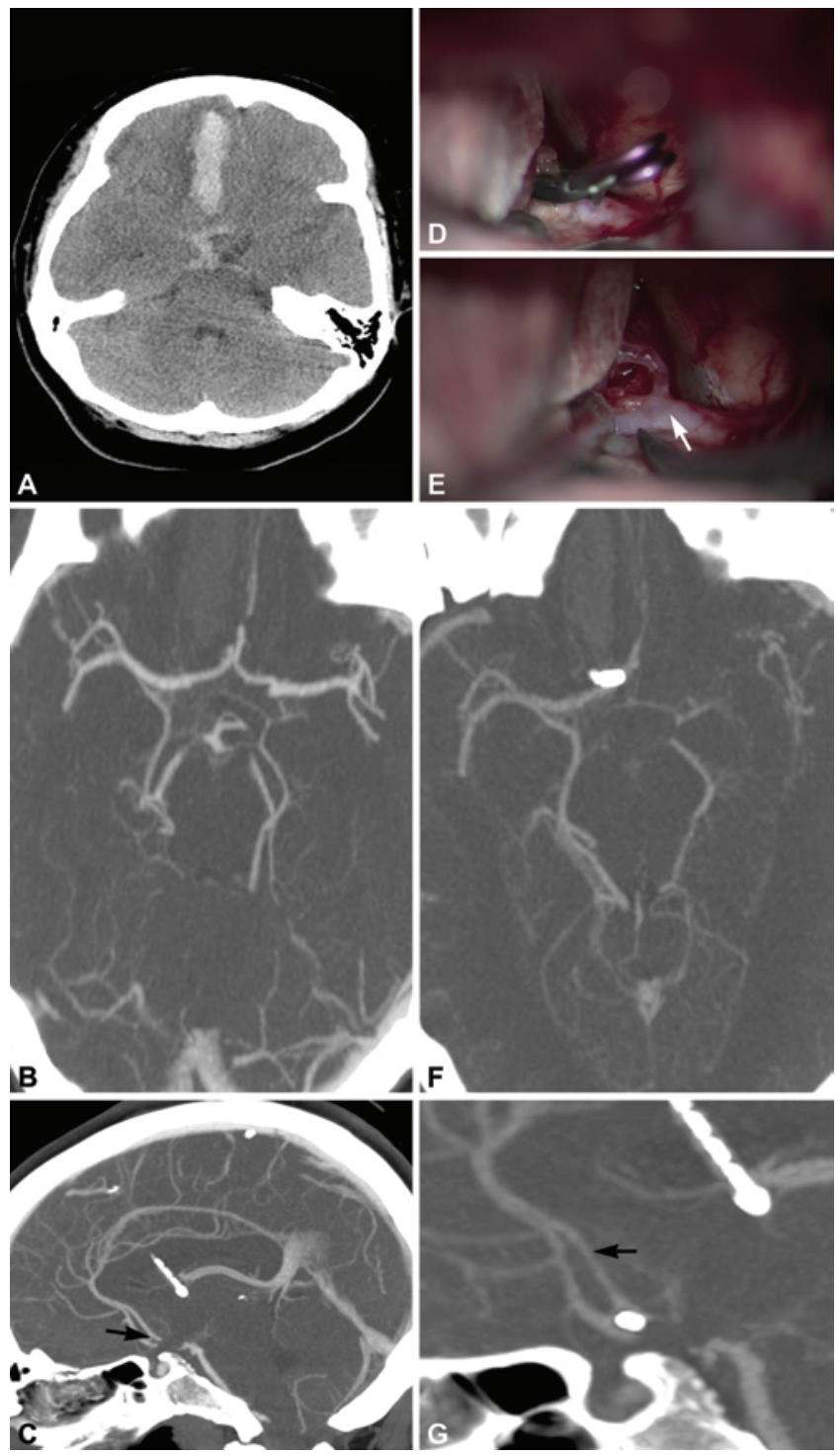

FIG. 3. Preoperative axial CT (A), axial CTA (B), and sagittal CT (C) images obtained in a patient with a ruptured, very small, broad-based, blister-like ACoA aneurysm. An intraoperative microsurgical image shows a small, broad-based, and very fragile aneurysm (D) of a fenestrated ACoA segment. The small size of the dome makes direct clip placement very intricate and increases the risk of the clip sliding off the aneurysm wall and causing tears in the parent vessel wall or the aneurysm base. Therefore, cotton is wrapped around the site of the aneurysm (Video 1) and the aneurysm is successfully clipped over the cotton ( $\mathbf{E}$, arrow). Cotton is used in this case because the fenestrated ACoA segment is too small and tight to accommodate a Gore-Tex wrap. The risk of parent vessel stenosis due to circumferential cotton wrap is acceptable in this case because of a fenestrated redundant ACoA complex. Postoperative CTA (F, axial; $\mathbf{G}$, sagittal) shows complete obliteration of the small aneurysm (arrows) without any compromise of the flow in the $A_{2}$ segments (G).

however, the current study is the first long-term series verifying its durability. There were no recurrences or complications, such as parent vessel stenosis, using the cottonclip technique in 23 patients with long-term follow-up in our series. Fusiform aneurysms are usually best treated with clip-wrapping techniques. ${ }^{3,15}$ However, fusiform and 

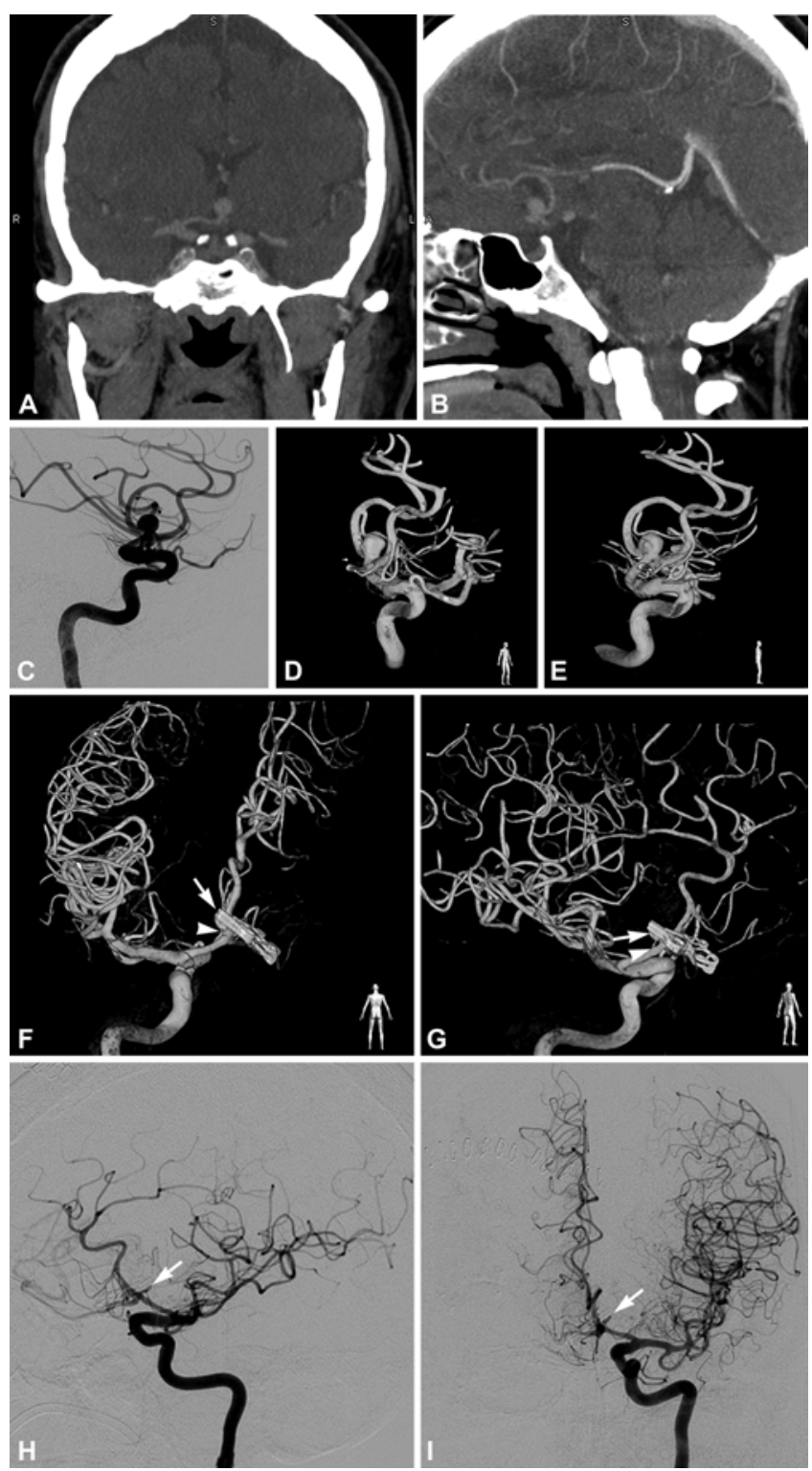

FIG. 4. Preoperative coronal (A) and sagittal (B) CTA images, digital subtraction angiogram (C), and 3D (D and E) angiographic images show a large ACoA aneurysm. The aneurysm dome is clip-reconstructed with 2 aneurysm clips using a tandem-clipping technique (F-I). There is an unclipped remnant at the base of the aneurysm (F-I, arrows) to protect a small perforating branch ( $\mathbf{F}$ and $\mathbf{G}$, arrowheads) best seen on the $3 \mathrm{D}$ reconstructions.

dissecting aneurysms, especially in the posterior circulation, are frequently difficult to manage with clip-wrapping techniques due to the significant likelihood of perforator involvement as well as the depth of the corridor of exposure (Video 2). ${ }^{15}$ These aneurysms can also be augmented with wisps of cotton placed around the diseased segment when circumferential wrapping with Gore-Tex is not possible (Video 3). Furthermore, clip-reconstruction and cotton-augmentation of residual aneurysms can be performed when perforators are incorporated into the aneurysmal segment or for aneurysms with heavy calcifications that prevent complete clipping (Fig. 4).

\section{Rates of Recurrence and Rebleeding in Residual Aneurysms}

Late re-rupture after treatment of ruptured intracranial aneurysms with either coil embolization or surgical clipping is rare.$^{32}$ However, early re-rupture within the 1 st year of treatment occurs more frequently and has major consequences..$^{32}$ In the Cerebral Aneurysm Rerupture After Treatment (CARAT) study, the overall risk of re-rupture in the 1st year after treatment was found to be $1.8 \% .^{32}$ Similarly, the International Subarachnoid Aneurysm Treatment (ISAT) trial found a $1.7 \%$ risk of re-rupture in the 1 st year. ${ }^{53}$ Several studies have suggested that subtotal occlusion of an aneurysm either with a surgical clip or with coils is associated with a significantly higher risk of subsequent hemorrhage compared with complete occlusion..$^{14,32}$ Overall, the incidence of residual aneurysms after clipping is estimated to range between $4 \%$ and $18 \% .^{14,32,39,48,68,69} \mathrm{Al}-$ though some residual aneurysms may undergo spontaneous thrombosis, others may enlarge and cause recurring hemorrhage..$^{4,23,68,70}$ The reported risk of hemorrhage from an aneurysm residuum varies and, depending on the location and the size of the remnant, is between $3.5 \%$ and $28 \% .^{14,23,32,39}$ However, even complete aneurysm occlusion does not guarantee prevention of re-rupture, and the risk of re-rupture for completely occluded aneurysms may be as high as $1.1 \%$ during the 1 st year..$^{32}$ The overall annual recurrence and hemorrhage rates of cotton-augmented, incompletely clipped aneurysms in the current series $(0.52 \%$ and $1.03 \%$, respectively) are much lower than our previously reported risk of recurrence from an aneurysm residuum of $2.9 \%$ per year, as well as risk of hemorrhage from an aneurysm remnant of $1.5 \%$ per year. ${ }^{14}$

Furthermore, it must be stressed that in the current series the only recurrent subarachnoid hemorrhage was encountered in a patient with a small broad-based aneurysm. We recognized previously that these aneurysms may constitute a completely separate subtype with a higher risk of recurrent hemorrhage. ${ }^{14,35}$ In the current series with 20 such broad-based aneurysms and mean follow-up of approximately 5 years, the patients had no rebleeding episodes or parent vessel stenoses when the cotton-clipping technique was used and only one late rebleed $(5 \%)$ when clipping and cotton-augmentation were used. Our prior experience with clip ligation of these broad-based aneurysms without the use of cotton showed a much higher annual recurrence rate (19\%). ${ }^{14}$ Although our study indicates that cotton can be used safely and without complications, it remains to be determined whether cotton-augmentation truly changes the natural history of aneurysm remnants. Nevertheless, given that incomplete aneurysm occlusion is a strong predictor of risk of re-rupture, with most reruptures occurring during the 1st year after treatment and especially during the first days after aneurysm obliteration, ${ }^{8,32}$ our study suggests that cotton-augmentation may provide a degree of protection reducing the risk of early re-rupture from aneurysm remnants.

\section{Limitations}

The retrospective nature of this study limits the strength of our conclusions. The median follow-up period for our 
patients was 70 months, which is still inadequate to determine the true long-term benefits of this technique. Several studies have shown that the risk of re-rupture may remain for several decades after treatment. ${ }^{69,70}$ The use of cotton is a bailout strategy for difficult-to-treat aneurysms and no prior study has looked at the long-term outcome of these patients. Direct comparisons between the outcomes of patients treated with this technique and historical controls would be very difficult given that these techniques are applied to a very select and challenging subset of lesions.

Despite the well-known inherent shortcomings of retrospective studies, we believe that our experience suggests several conclusions.

\section{Conclusions}

Cotton-clipping for the treatment of aneurysms is a safe and durable technique without acute or delayed postoperative complications. Cotton-clipping is especially effective for managing intraoperative rupture of an aneurysm neck and for managing broad-based aneurysms without an adequate reconstructable neck. Cotton-augmentation can be safely used to manage unclippable or partially clippable intracranial aneurysms and provides promising protection from early aneurysm re-rupture. It remains to be determined whether cotton-augmentation provides protection from growth and late subarachnoid hemorrhage of an unclipped aneurysm remnant. The overall rates of regrowth and re-rupture were relatively low in this series.

\section{References}

1. Artmann H, Vonofakos D, Müller H, Grau H: Neuroradiologic and neuropathologic findings with growing giant intracranial aneurysm. Review of the literature. Surg Neurol 21:391-401, 1984

2. Barrow DL, Spetzler RF: Cotton-clipping technique to repair intraoperative aneurysm neck tear: a technical note. Neurosurgery 68 (2 Suppl Operative):294-299, 2011

3. Bederson JB, Zabramski JM, Spetzler RF: Treatment of fusiform intracranial aneurysms by circumferential wrapping with clip reinforcement. Technical note. J Neurosurg 77:478-480, 1992

4. Beitzke M, Leber KA, Deutschmann H, Gattringer T, Poltrum B, Fazekas F: Cerebrovascular complications and granuloma formation after wrapping or coating of intracranial aneurysms with cotton gauze and human fibrin adhesives: results from a single-center patient series over a 5-year period. J Neurosurg 119:1009-1014, 2013

5. Berger C, Hartmann M, Wildemann B: Progressive visual loss due to a muslinoma-report of a case and review of the literature. Eur J Neurol 10:153-158, 2003

6. Bhatti MT, Holder CA, Newman NJ, Hudgins PA: MR characteristics of muslin-induced optic neuropathy: report of two cases and review of the literature. AJNR Am J Neuroradiol 21:346-352, 2000

7. Brochert A, Reynolds T, Baker R: MRI in a case of muslininduced granuloma. Neuroradiology 45:82-84, 2003

8. CARAT Investigators: Rates of delayed rebleeding from intracranial aneurysms are low after surgical and endovascular treatment. Stroke 37:1437-1442, 2006

9. Carney PG, Oatey PE: Muslin wrapping of aneurysms and delayed visual failure. A report of three cases. J Clin Neuroophthalmol 3:91-96, 1983

10. Chambi I, Tasker RR, Gentili F, Lougheed WM, Smyth HS,
Marshall J, et al: Gauze-induced granuloma ("gauzoma"): an uncommon complication of gauze reinforcement of berry aneurysms. J Neurosurg 72:163-170, 1990

11. Cohen MM, Hemalatha CP, D'Addario RT, Goldman HW: Embolization from a fusiform middle cerebral artery aneurysm. Stroke 11:158-161, 1980

12. Cossu M, Pau A, Turtas S, Viola C, Viale GL: Subsequent bleeding from ruptured intracranial aneurysms treated by wrapping or coating: a review of the long-term results in 47 cases. Neurosurgery 32:344-347, 1993

13. Cudlip SA, Kitchen ND, McKhahn GM, Bell BA: Wrapping of solitary ruptured intracranial aneurysms, outcome at five years. Acta Neurochir (Wien) 140:1167-1171, 1998

14. David CA, Vishteh AG, Spetzler RF, Lemole M, Lawton MT, Partovi S: Late angiographic follow-up review of surgically treated aneurysms. J Neurosurg 91:396-401, 1999

15. Deshmukh VR, Kakarla UK, Figueiredo EG, Zabramski JM, Spetzler RF: Long-term clinical and angiographic follow-up of unclippable wrapped intracranial aneurysms. Neurosurgery 58:434-442, 2006

16. Drake CG, Friedman AH, Peerless SJ: Failed aneurysm surgery. Reoperation in 115 cases. J Neurosurg 61:848-856, 1984

17. Drake CG, Vanderlinden RG: The late consequences of incomplete surgical treatment of cerebral aneurysms. J Neurosurg 27:226-238, 1967

18. Dutton J: Acrylic investment of intracranial aneurysms. BMJ 2:597-602, 1959

19. Ebina K, Iwabuchi T, Suzuki S: A clinico-experimental study on various wrapping materials of cerebral aneurysms. Acta Neurochir (Wien) 72:61-71, 1984

20. Ebina K, Suzuki M, Andoh A, Saitoh K, Iwabuchi T: Recurrence of cerebral aneurysm after initial neck clipping. Neurosurgery 11:764-768, 1982

21. Elijovich L, Higashida RT, Lawton MT, Duckwiler G, Giannotta S, Johnston SC: Predictors and outcomes of intraprocedural rupture in patients treated for ruptured intracranial aneurysms: the CARAT study. Stroke 39:1501-1506, 2008

22. Felsberg GJ, Tien RD, Haplea S, Osumi AK: Muslin-induced optic arachnoiditis ("gauzoma"): findings on CT and MR. J Comput Assist Tomogr 17:485-487, 1993

23. Feuerberg I, Lindquist C, Lindqvist M, Steiner L: Natural history of postoperative aneurysm rests. J Neurosurg 66:3034, 1987

24. Frösen J, Piippo A, Paetau A, Kangasniemi M, Niemelä M, Hernesniemi J, et al: Remodeling of saccular cerebral artery aneurysm wall is associated with rupture: histological analysis of 24 unruptured and 42 ruptured cases. Stroke 35:22872293, 2004

25. Fujimura M, Nishijima M, Umezawa K, Hayashi T, Mino Y, Sakuraba T, et al: Optochiasmal arachnoiditis following cotton wrapping of anterior communicating artery aneurysm treated by surgical removal of granuloma. J Clin Neurosci 10:254-257, 2003

26. Fujiwara S, Fujii K, Nishio S, Fukui M: Long-term results of wrapping of intracranial ruptured aneurysms. Acta Neurochir (Wien) 103:27-29, 1990

27. Germanò A, Priola S, Angileri FF, Conti A, La Torre D, Cardali S, et al: Long-term follow-up of ruptured intracranial aneurysms treated by microsurgical wrapping with autologous muscle. Neurosurg Rev 36:123-132, 2013

28. Giannotta SL, Oppenheimer JH, Levy ML, Zelman V: Management of intraoperative rupture of aneurysm without hypotension. Neurosurgery 28:531-536, 1991

29. Goldsberry DH, Ross IB, Dhillon G, Corbett JJ: Visual dysfunction caused by gauze wrapping of an intracranial aneurysm. J Neuroophthalmol 24:42-45, 2004

30. Haisa T, Matsumiya K, Yoshimasu N, Kuribayashi N: Foreign-body granuloma as a complication of wrapping and 
coating an intracranial aneurysm. Case report. J Neurosurg 72:292-294, 1990

31. Herrera O, Kawamura S, Yasui N, Yoshida Y: Histological changes in the rat common carotid artery induced by aneurysmal wrapping and coating materials. Neurol Med Chir (Tokyo) 39:134-140, 1999

32. Johnston SC, Dowd CF, Higashida RT, Lawton MT, Duckwiler GR, Gress DR: Predictors of rehemorrhage after treatment of ruptured intracranial aneurysms: the Cerebral Aneurysm Rerupture After Treatment (CARAT) study. Stroke 39:120-125, 2008

33. Kalani MY, Elhadi AM, Ramey W, Nakaji P, Albuquerque FC, McDougall CG, et al: Revascularization and pediatric aneurysm surgery. J Neurosurg Pediatr 13:641-646, 2014

34. Kalani MY, Ramey W, Albuquerque FC, McDougall CG, Nakaji P, Zabramski JM, et al: Revascularization and aneurysm surgery: techniques, indications, and outcomes in the endovascular era. Neurosurgery 74:482-498, 2014

35. Kalani MY, Zabramski JM, Kim LJ, Chowdhry SA, Mendes GA, Nakaji P, et al: Long-term follow-up of blister aneurysms of the internal carotid artery. Neurosurgery 73:1026-1033, 2013

36. Kawamura S, Hadeishi H, Suzuki A, Yasui N: Arterial occlusive lesions following wrapping and coating of unruptured aneurysms. Neurol Med Chir (Tokyo) 38:12-19, 1998

37. Kim C, Kikuchi H, Hashimoto N, Kojima M, Kang Y, Hazama F: Involvement of internal elastic lamina in development of induced cerebral aneurysms in rats. Stroke 19:507-511, 1988

38. Kirollos RW, Tyagi AK, Marks PV, van Hille PT: Muslin induced granuloma following wrapping of intracranial aneurysms: the role of infection as an additional precipitating factor. Report of two cases and review of the literature. Acta Neurochir (Wien) 139:411-415, 1997

39. Kivisaari RP, Porras M, Ohman J, Siironen J, Ishii K, Hernesniemi J: Routine cerebral angiography after surgery for saccular aneurysms: is it worth it? Neurosurgery 55:1015-1024, 2004

40. Kurokawa Y, Wanibuchi M, Ishiguro M, Inaba K: New method for obliterative treatment of an anterior wall aneurysm in the internal carotid artery: encircling silicone sheet clip procedure-technical case report. Neurosurgery 49:469-472, 2001

41. Kuroki T, Aoki K, Aoki Y, Nemoto A, Yamazaki T, Katsume $\mathrm{M}$, et al: Cranial nerve pareses following wrapping of a ruptured dissecting vertebral artery aneurysm: a possible complication of cyanoacrylate glue-case report. Neurol Med Chir (Tokyo) 43:35-37, 2003

42. Lanzino G, Spetzler RF: Clip wrapping for partial avulsion of the aneurysm neck. Technical note. J Neurosurg 99:931932, 2003

43. Lavin P: Muslin-induced optochiasmatic arachnoiditis? Neurosurgery 20:505, 1987 (Letter)

44. Lawton MT, Du R: Effect of the neurosurgeon's surgical experience on outcomes from intraoperative aneurysmal rupture. Neurosurgery 57:9-15, 2005

45. Lee DW, Binning MJ, Shanmugam VK, Schmidt RH, Couldwell WT, Meyer M, et al: Muslin-induced intracranial vasculopathic stenosis: a report of two cases. Clin Neurol Neurosurg 114:63-67, 2012

46. Leipzig TJ, Morgan J, Horner TG, Payner T, Redelman K, Johnson CS: Analysis of intraoperative rupture in the surgical treatment of 1694 saccular aneurysms. Neurosurgery 56:455-468, 2005

47. Lin T, Fox AJ, Drake CG: Regrowth of aneurysm sacs from residual neck following aneurysm clipping. J Neurosurg 70:556-560, 1989

48. Macdonald RL, Wallace MC, Kestle JR: Role of angiography following aneurysm surgery. J Neurosurg 79:826-832, 1993
49. McFadzean RM, Hadley DM, McIlwaine GG: Optochiasmal arachnoiditis following muslin wrapping of ruptured anterior communicating artery aneurysms. J Neurosurg 75:393-396, 1991

50. Mérei FT, Gallyas F: Role of the structural elements of the arterial wall in the formation and growth of intracranial saccular aneurysms. Neurol Res 2:283-303, 1980

51. Mickey BE, Samson D: Neurosurgical applications of the cyanoacrylate adhesives. Clin Neurosurg 28:429-444, 1981

52. Minakawa T, Koike T, Fujii Y, Ishii R, Tanaka R, Arai H: Long term results of ruptured aneurysms treated by coating. Neurosurgery 21:660-663, 1987

53. Molyneux AJ, Kerr RS, Yu LM, Clarke M, Sneade M, Yarnold JA, et al: International subarachnoid aneurysm trial (ISAT) of neurosurgical clipping versus endovascular coiling in 2143 patients with ruptured intracranial aneurysms: a randomised comparison of effects on survival, dependency, seizures, rebleeding, subgroups, and aneurysm occlusion. Lancet 366:809-817, 2005

54. Morioka M, Marubayashi T, Masumitsu T, Hori T, Ushio Y: Wrapping of intracranial aneurysms with gauze sponge. Neurol Med Chir (Tokyo) 31:135-140, 1991

55. Mount LA, Antunes JL: Results of treatment of intracranial aneurysms by wrapping and coating. J Neurosurg 42:189193, 1975

56. Onoue H, Abe T, Tashibu K, Suzuki T: Two undesirable results of wrapping of an intracranial aneurysm. Neurosurg Rev 15:307-309, 1992

57. Pool JL: Muslin gauze in intracranial vascular surgery. Technical note. J Neurosurg 44:127-128, 1976

58. Prabhu SS, Keogh AJ, Parekh HC, Perera S: Optochiasmal arachnoiditis induced by muslin wrapping of intracranial aneurysms. A report of two cases and a review of the literature. Br J Neurosurg 8:471-476, 1994

59. Sachs E Jr: The fate of muscle and cotton wrapped about intracranial carotid arteries and aneurysms. A laboratory and clinico-pathological study. Acta Neurochir (Wien) 26:121137,1972

60. Safavi-Abbasi S, Sun H, Oppenlander ME, Nakaji P, Kalani MY, Zabramski JM, et al: Repair of intraoperative aneurysm neck tear utilizing the cotton-clipping technique. Neurosurg Focus 38 (Video Suppl 1):Video14, 2015

61. Sato K, Fujiwara S, Kameyama M, Ogawa A, Yoshimoto T, Suzuki J: Follow-up study on ruptured aneurysms treated by wrapping. Neurol Med Chir (Tokyo) 30:734-737, 1990

62. Schaafsma JD, Sprengers ME, van Rooij WJ, Sluzewski M, Majoie CB, Wermer MJ, et al: Long-term recurrent subarachnoid hemorrhage after adequate coiling versus clipping of ruptured intracranial aneurysms. Stroke 40:1758-1763, 2009

63. Schramm J, Cedzich C: Outcome and management of intraoperative aneurysm rupture. Surg Neurol 40:26-30, 1993

64. Seifert VS, Stolke D, Trost HA, Brüning A, Schaffer J: Incidence, management, and outcome of patients with premature rupture of cerebral aneurysms during surgery, in Frowein RA, Brock M, Klinger M (eds): Head Injuries. Berlin: Springer, 1989

65. Shokunbi MT, Vinters HV, Kaufmann JC: Fusiform intracranial aneurysms. Clinicopathologic features. Surg Neurol 29:263-270, 1988

66. Spetzler RF, McDougall CG, Albuquerque FC, Zabramski JM, Hills NK, Partovi S, et al: The Barrow Ruptured Aneurysm Trial: 3-year results. J Neurosurg 119:146-157, 2013

67. Taylor JC, Choudhury AR: Reinforcement with gauze wrapping for ruptured aneurysms of the middle cerebral artery. J Neurosurg 47:828-832, 1977

68. Tsutsumi K, Ueki K, Morita A, Usui M, Kirino T: Risk of aneurysm recurrence in patients with clipped cerebral aneurysms: results of long-term follow-up angiography. Stroke 32:1191-1194, 2001 
69. Tsutsumi K, Ueki K, Usui M, Kwak S, Kirino T: Risk of recurrent subarachnoid hemorrhage after complete obliteration of cerebral aneurysms. Stroke 29:2511-2513, 1998

70. Wermer MJ, Greebe P, Algra A, Rinkel GJ: Incidence of recurrent subarachnoid hemorrhage after clipping for ruptured intracranial aneurysms. Stroke 36:2394-2399, 2005

71. Yaşargil MG: Microneurosurgery. New York: Thieme, 1984

72. Yoon MA, Kim E, Kwon BJ, Kim JE, Kang HS, Park JH, et al: Muslinoma and muslin-induced foreign body inflammatory reactions after surgical clipping and wrapping for intracranial aneurysms: imaging findings and clinical features. J Neurosurg 112:640-647, 2010

\section{Disclosures}

The authors report no conflict of interest concerning the materials or methods used in this study or the findings specified in this paper.

\section{Author Contributions}

Conception and design: Safavi-Abbasi. Acquisition of data:
Moron. Analysis and interpretation of data: Safavi-Abbasi. Drafting the article: Safavi-Abbasi, Sun, Oppenlander. Critically revising the article: Sun, Oppenlander, Kalani, Mulholland. Reviewed submitted version of manuscript: Nakaji, SafaviAbbasi, Zabramski, Spetzler. Administrative/technical/material support: Spetzler. Study supervision: Nakaji, Safavi-Abbasi, Zabramski, Spetzler.

\section{Supplemental Information}

Videos

Video 1. https://vimeo.com/140797220.

Video 2. https://vimeo.com/140797221.

Video 3. https://vimeo.com/140797219.

\section{Correspondence}

Peter Nakaji, c/o Neuroscience Publications, Barrow Neurological Institute, St. Joseph's Hospital and Medical Center, 350 W. Thomas Rd., Phoenix, AZ 85013.email: neuropub@ dignityhealth.org. 